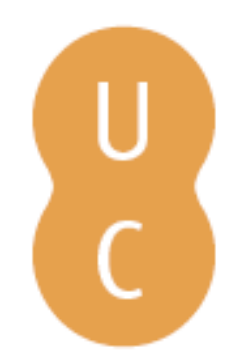

\title{
pommalina
}

\section{Geologia estrutural da Península Fildes, Ilha Rei George, Antárctida}

\author{
Autor(es): $\quad$ Machado, Adriane; Barata, Teresa; Chemale Jr., Farid; Canale, André; \\ Karmman, Ivo
}

Publicado por: Imprensa da Universidade de Coimbra; Laboratório de Radioactividade

URL persistente: Natural da Universidade de Coimbra

DOI:

URI:http://hdl.handle.net/10316.2/36306

DOl:http://dx.doi.org/10.14195/978-989-26-1009-2_17

Accessed : $\quad$ 26-Apr-2023 13:58:27

A navegação consulta e descarregamento dos títulos inseridos nas Bibliotecas Digitais UC Digitalis, UC Pombalina e UC Impactum, pressupõem a aceitação plena e sem reservas dos Termos e Condições de Uso destas Bibliotecas Digitais, disponíveis em https://digitalis.uc.pt/pt-pt/termos.

Conforme exposto nos referidos Termos e Condições de Uso, o descarregamento de títulos de acesso restrito requer uma licença válida de autorização devendo o utilizador aceder ao(s) documento(s) a partir de um endereço de IP da instituição detentora da supramencionada licença.

Ao utilizador é apenas permitido o descarregamento para uso pessoal, pelo que o emprego do(s) título(s) descarregado(s) para outro fim, designadamente comercial, carece de autorização do respetivo autor ou editor da obra.

Na medida em que todas as obras da UC Digitalis se encontram protegidas pelo Código do Direito de Autor e Direitos Conexos e demais legislação aplicável, toda a cópia, parcial ou total, deste documento, nos casos em que é legalmente admitida, deverá conter ou fazer-se acompanhar por este aviso.

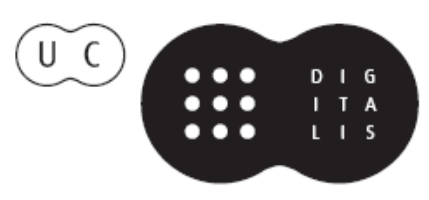




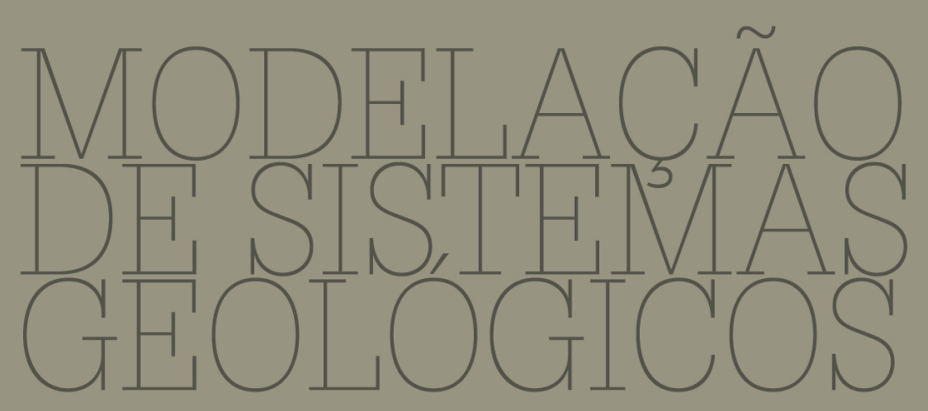

Homenagem ao Professor Doutor Manuel Maria Godinho

L.J.P.F. Neves, A.J.S.C. Pereira,

C.S.R. Gomes, L.C.G. Pereira,

A.O. TAVARES

IMPRENSA DA UNIVERSIDADE DE COIMBRA

CoImBra University Press 


\title{
MODELAÇÃO \\ DE SISTEMAS \\ GEOLÓGICOS
}

Homenagem ao Professor Manuel Maria Godinho

\section{Geologia estrutural da Península Fildes, Ilha Rei George, Antárctida}

\author{
Adriane Machado ${ }^{1}$; Teresa Barata ${ }^{1}$; Farid Chemale Jr. ${ }^{2}$; André Canale ${ }^{3}$; Ivo \\ Karmman ${ }^{4}$ \\ ${ }^{1}$ Centro de Geofísica da Universidade de Coimbra, PORTUGAL, adrianemachado@ci.uc.pt; \\ mtbarata@gmail.com \\ ${ }^{2}$ Instituto de Geociências da Universidade de Brasília, BRASIL, farid.chemale@ufs.br \\ ${ }^{3}$ Instituto de Geociências da Universidade Federal do Rio Grande do Sul, Porto Alegre, BRASIL \\ ${ }^{4}$ Instituto de Geociências da Universidade de São Paulo, BRASIL
}

Palavras-chave: Tectónica extensional, Subducção, Ilhas Shetland do Sul

\section{Resumo}

A tectónica dominante na Península Fildes é de carácter extensional, com geração de falhas normais e transcorrentes em regime rúptil. Em geral, as estruturas primárias como o fluxo de lava e acamamento sedimentar, afloram com orientação horizontal a subhorizontal, levemente basculadas, evidenciando a fraca deformação na região durante o processo de subducção entre as placas Phoenix/Drake-Antárctida. Os sistemas principais de falhas e fracturas são de direcção E-W com mergulhos subverticais a verticais e, secundariamente $\mathrm{N}-\mathrm{S}$ e $\mathrm{N} 20^{\circ}-45^{\circ} \mathrm{E}$, com mergulhos normalmente elevados.

Key-words: Extensional tectonic, Subduction, South Shetland Islands

\section{Abstract}

The dominant tectonic in Fildes Peninsula is extensional showing the formation of normal and transcurrent (strike-slip) faults in a ruptile regime. The primary structures such as lava flows and sedimentary bedding, which are lightly basculated, show mostly horizontal to subhorizontal orientation. This suggests a weak deformation in the area during the subduction process among the Phoenix/Drake-Antarctica plates. The major fault and fracture systems are E-W oriented close to $90^{\circ}$ dip and secondarily $N-S$ and $N 20^{\circ}-45^{\circ} E$ oriented with regular steep dips.

\section{Introdução}

A Península Fildes localiza-se no sudoeste da Ilha Rei George $\left(62^{\circ} 13^{\prime} \mathrm{S}\right.$, $\left.58^{\circ} 54^{\prime} \mathrm{W}\right)$, sendo a maior ilha do Arquipélago Shetland do Sul, Antárctida (Figura 1). A formação do arquipélago é o resultado da actividade 
magmática gerada pelo processo de subducção entre as placas Phoenix/Drake-Antárctida (Figura 1) durante o Meso-Cenozóico num ambiente de arco-de-ilhas (Smellie et al., 1984; Cande et al., 2000). No final do Terciário, o arquipélago passou por um processo extensional regional, tendo originado o Estreito de Bransfield (Figura 1).

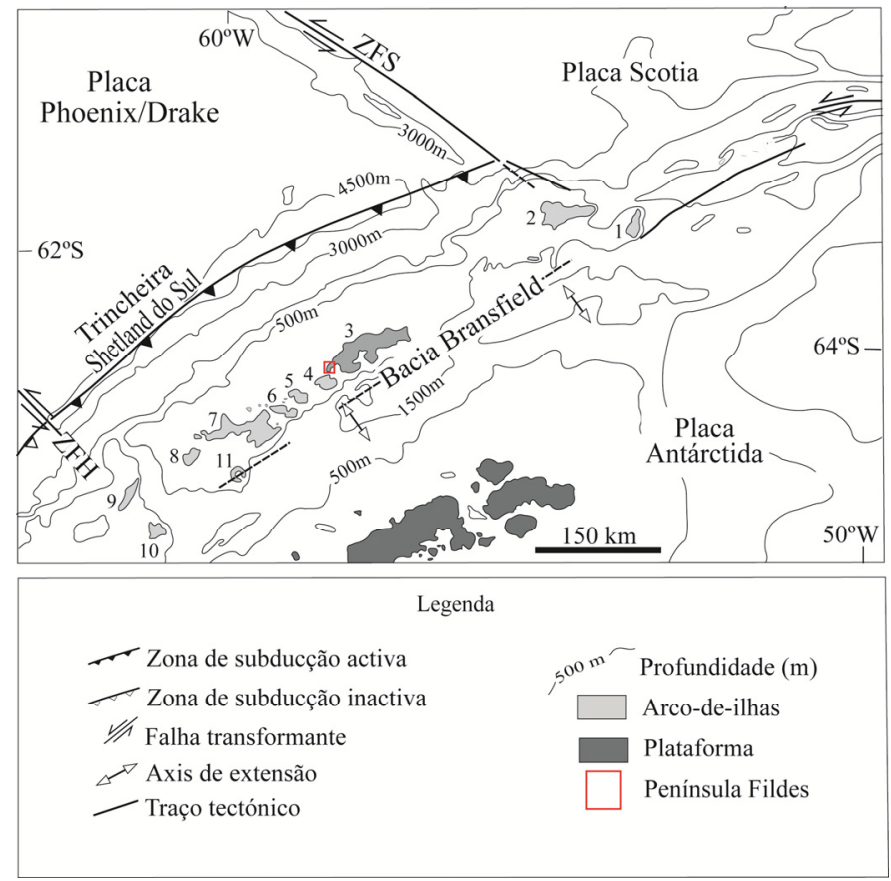

Figura 1. Contexto tectónico das Ilhas Shetland do Sul. (1) Ilha Clarence; (2) Ilha Elefante; (3) Ilha Rei George; (4) Ilha Nelson; (5) Ilha Robert; (6) Ilha Greenwich; (7) Ilha Livingston; (8) Ilha Snow; (9) Ilha Smith; (10) Ilha Low e (11) Ilha Deception (Lawver et al., 1996).

O levantamento da geologia estrutural evidenciou que a Península Fildes apresenta como estruturas primárias principais o bandado ígneo (estrutura de fluxo) e a estratificação sedimentar plano-paralela, que em geral, são bem visíveis nos afloramentos. As maiorias das estruturas primárias estão subhorizontais e, eventualmente, observam-se blocos com mergulhos maiores que $30^{\circ}$, impedindo muitas vezes de estabelecer a continuidade entre os blocos.

Em termos estruturais identificam-se sistemas de lineamentos com orientação N-S, N30-40E e WNW-ESSE, visualizados frequentemente nos afloramentos. Estas estruturas apresentam indicadores cinemáticos de 
movimento normal e direccional, e são acompanhadas por um conjunto de sistemas de fracturas e falhas, de tamanho métrico a centimétrico.

Os trabalhos de campo permitiram reconhecer diferentes conjuntos de fracturas e falhas, gerados num ambiente rúptil. Localmente, identificaramse micro-dobras centimétricas em rochas epiclásticas.

\section{Metodologia}

O tratamento dos dados estruturais da Península Fildes compreendeu medidas de atitudes de fracturas, classificadas como simples e preenchidas, e subdivididas em pequenas $(1$ a $5 \mathrm{~m})$, médias $(5$ a $10 \mathrm{~m})$ e grandes $(>10$ m). A observação dos dados planares permitiu o reconhecimento dos principais padrões da deformação rúptil, detectados nas rochas vulcânicas e vulcanoclásticas da Península Fildes.

Os dados estruturais foram interpretados através da projecção em estereogramas, com os pólos dos planos de fracturas acompanhados pelas atitudes dos planos nas suas máximas concentrações. Os estereogramas foram obtidos utilizando-se os programas GELI, Monitor e StereoNet. Para o tratamento dos dados utilizaram-se combinações entre os diversos tipos de fracturas, com o objetivo de obter informações referentes aos padrões de direcção e mergulho. Em geral, foram utilizados diagramas com o mínimo de 50 medidas planares, preferencialmente de um mesmo afloramento; caso contrário, optou-se por utilizar agrupamento de áreas contíguas.

\section{Resultados e discussão}

A feição planar mais evidente na Península Fildes é a estratificação primária, como o bandado dado pelo fluxo de lava e estratificação planoparalela nas rochas epiclásticas. As estruturas secundárias da Península Fildes são falhas normais e transcorrentes, bem como sistemas de fracturas com mergulhos subverticais, todos formados em ambiente rúptil. Por outro lado, observa-se em campo, que as camadas de lavas intercaladas com vulcanoclásticas formam blocos com a continuidade da estratificação original visível. No entanto, entre estes blocos não é possível acompanhar a continuidade das camadas guias. Assim, pressupõe-se que elas estejam basculadas.

Em geral, podem-se diferenciar como sistemas de falhas principais (lineamentos), todos aqueles com atitude E-W, N-S e N30-40E. No afloramento, as estruturas E-W com mergulho subvertical (fracturas não preenchidas) e E-W/69 a 066-075/subvertical (fracturas preenchidas) são as 
modas mais frequentes. A análise individual dos tipos de fracturas também indica o domínio de estruturas com orientação N-S e E-W, subordinadamente às NE.

A cinemática dos falhamentos N-S e E-W foi identificada através de estrias (Figura 2a), de estruturas anastomosadas (Figura 2b) e pelo deslocamento da estratificação primária. Muitas das estruturas com mesma orientação espacial apresentam movimentos ora normal, ora direccional. Tal facto pode ser explicado por movimentos distintos associados a dois eventos tectónicos, como por exemplo, um associado ao processo de subducção meso-cenozóica e outro, ao processo de rifte do Estreito de Bransfield.

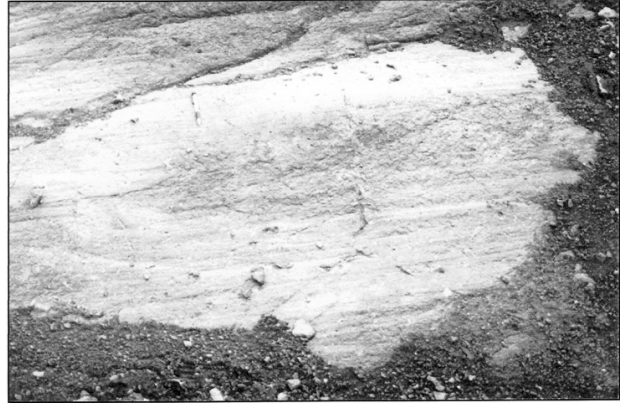

(a)

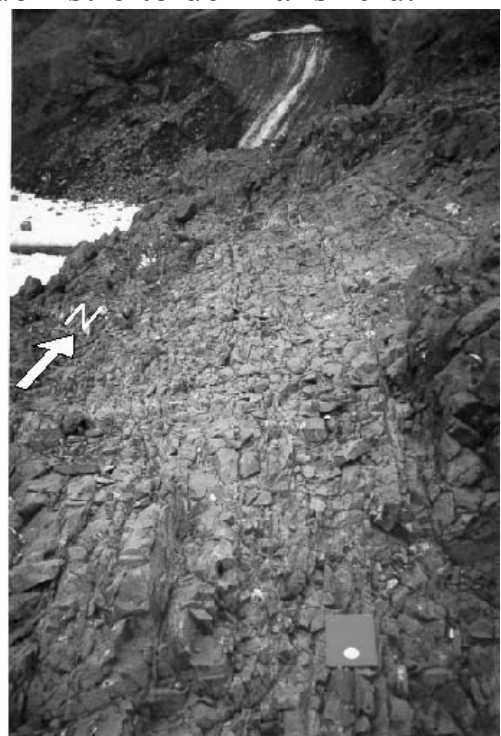

(b)

Figura 2. a) Estrias horizontais relacionadas a uma falha transcorrente; b) Sistema de falhas transcorrentes com orientação NW e estrutura anastomosada (Machado, 1997).

No presente trabalho não foi possível diferenciar cronologicamente os eventos tectónicos, devido às rochas da Península Fildes apresentarem idades quase exclusivamente do Terciário Inferior, enquanto que as deformações ocorreram entre o Terciário Inferior e Quaternário, todas em regime rúptil. Não se identificaram minerais gerados durante as deformações para datá-los. Por outro lado, o acervo de estruturas primárias e secundárias estudados, sugere que o tipo de deformação dominante no Terciário Inferior foi extensional. Tal facto baseia-se em estudos tectónicos de bacias extensionais (riftes intracontinentais e margens passivas) em que as estruturas identificadas são muito semelhantes às aqui descritas. 
Durante o trabalho não foram encontradas estruturas tectónicas indicativas de processo compressional, como é usualmente descrito para as regiões formadas em ambiente de arco-de-ilhas (Condie, 1989), como dobras e falhas ligadas a processos de empurrões. Deve-se ressaltar que muitos autores descrevem a presença de estruturas tectónicas associadas a processos de compressão ou inversão estratigráfica para outras áreas da Ilha Rei George (Barton, 1965).

Nos últimos anos tem-se discutido muito sobre os tipos de estruturas tectónicas presentes em arcos-de-ilhas, quer ao nível de superfície (com base nos trabalhos de campo), como em subsuperfície (com base a secções sísmicas). Vários autores chegaram à conclusão que a maioria dos modelos de arcos-de-ilhas incorpora a idéia errónea de que as placas oceânicas subductantes escorregam em direção a uma placa fixa (ou bloco fixo), o que levaria então, à geração de estruturas nitidamente compressionais. No entanto, tem-se observado que as estruturas dominantes em arcos-de-ilhas modernos como Java, Japão, Aleutas, entre outros, são nitidamente extensionais. Constatou-se então que o regime tectónico comum em placas convergentes, com formação de arco-de-ilhas, é o extensional, já que a região de fore arc, onde as rochas deveriam estar invertidas por tectónica de empurrão e dobramento, desliza por cima da placa oceânica, que mergulha mais ingrememente (Hamilton, 1995). Assim, a região de fore arc não permanece fixa em relação ao movimento da placa subductante, mas sim, movimenta-se sobre esta com dominância de tectonismo extensional na primeira.

Ainda que este trabalho não seja conclusivo para a Ilha Rei George e mesmo para as Ilhas Shetland do Sul, deve-se investigar qual o tipo de regime que gerou as estruturas descritas como compressionais, mencionadas por outros autores noutras áreas da Ilha Rei George e demais ilhas do arquipélago. Deve-se avaliar qual a importância da tectónica compressional durante a formação do arco-de-ilhas Shetland do Sul no decorrer do Terciário.

\section{Conclusão}

As falhas na Península Fildes apresentam indicadores cinemáticos de movimentos normais e transcorrentes, todos gerados em ambiente rúptil. Os dados estruturais definem padrões de lineamentos megascópicos E-W, N-S e N30-40E, enquanto que nos afloramentos dominam as fracturas preenchidas de direção E-W com mergulho subvertical e fracturas não preenchidas, segundo a orientação E-W/69 e N66-75E/subvertical. 
A tectónica vigente durante o Terciário Inferior, época em que as rochas vulcânicas da Península Fildes se formaram, foi de carácter extensional. Não há registo, na área de estudo, de estruturas secundárias formadas em regime compressional (empurrão). O processo de extensão a que foi submetida à região das Ilhas Shetland do Sul no final do Cenozóico, gerou o Estreito de Bransfield, contribuindo para que estruturas extensionais e direccionais tenham sido reactivadas.

\section{Bibliografia}

Barton, C.M. (1965) - The geology of South Shetland Islands. III. The stratigraphy of King George Island. British Antarctic Survey, Scientific Reports, London; 44, 33 pp.

Cande, S.R., Stock, J.M., Müller, R.D., Ishihara, T. (2000) - Cenozoic motion between East and West Antarctica. Nature; 404, 145-150.

Condie, K.C. (1989) - Plate tectonics and crustal evolution. Pergamon, New York, $3^{\mathrm{a}}$ ed.

Hamilton, W.B. (1995) - Subduction systems and magmatism. John L. Smellie (ed.), Volcanism Associated with Extension at Consuming Plate Margins, Geological Society Special Publication; 81, 3-28.

Lawver, A.L., Sloan, B.J., Barker, D.H.N., Ghidella, M., Von Herzen, R.P., Keller, R.A., Klinkhammer, G.P., Chin, C.S. (1996) - Distributed, Active Extension in Bransfield Basin, Antarctic Peninsula: Evidence from Multibeam Bathymetry. GSA Today; 6(11), 1-5.

Machado, A. (1997) - Petrologia, Geoquímica e Geologia Estrutural da Península Fildes. Ilha Rei George, Antártica. Dissertação de Mestrado, Instituto de Geociências, Universidade Federal do Rio Grande do Sul, Brasil.

Smellie, J.L.; Pankhurst, R.; Thomson, M.R.A.; Davies, R. (1984) - The geology of the South Shetland Islands: Stratigraphy, geochemistry and evolution. British Antarctic Survey Scientific Reports, 87. 